\title{
Perceived fertility desires of spouses and use of modern contraception among women in Rakai, Uganda
}

Tom Lutalo ${ }^{*}$, Fredrick Makumbi ${ }^{2}$,John Santelli³ ${ }^{3}$ David Guwatudde ${ }^{2}$, Heena Brahmbhatt ${ }^{4}$, Sanyukta Mathur ${ }^{5}$, David Serwadda ${ }^{2}$, Fred Nalugoda ${ }^{1}$, Robert Ssekubugu ${ }^{1}$, Maria Wawer ${ }^{6}$, Ron Gray ${ }^{6}$

${ }^{1}$ Rakai Health Sciences Program, Uganda Virus Research Institute, Entebbe, Uganda

${ }^{2}$ Makerere University School of Public Health, Kampala, Uganda

3Joseph L Mailman School of Public Health, Columbia University, New York, USA

${ }^{4}$ Department of Population, Family and Reproductive Health, Johns Hopkins Bloomberg School of Public Health, Baltimore, MD, USA

${ }^{5}$ Population Council, Washington, USA

${ }^{6}$ Department of Epidemiology, Johns Hopkins Bloomberg School of Public Health, Baltimore, MD, USA

\begin{abstract}
Most societies in Sub Saharan Africa are patriarchal with major decisions made by men. However studies on family planning mostly focus on women and ignore power dynamics within relationships. Here we use data collected between 2013 and 2015 from 2636 couples, part of a community based cohort, with the aim of assessing how women's perception of their spouse's fertility desires affects her use of modern contraception. We used mediation analysis for this. We also used Chisquare tests to assess how accurate women's perception of her spouse's fertility desires was by comparing it with her partner's reported fertility desires. We found that in $53.9 \%$ of the couples there was concordance between the female's perception of their male spouse's fertility desires and the reported fertility desires of the male spouse. However is $28.9 \%$ of couples females thought the man desired a child while the male did not desire a child. We also found that female's fertility desires were indirectly influenced by their perceptions of the male spouse's fertility desires which affected their use of modern contraception. This indirect effect was statistically significant $(11 \%$; $\mathrm{p} 0.001)$. There is a need to promote increased spousal communication which would help merge perceptions and actual desires within a couple in this setting. This would help reduce the high rates of unmet need for contraception observed in similar settings.
\end{abstract}

\section{Introduction}

Many Sub Saharan Africa (SSA) societies are patriarchal with social power held by men $[1,2]$. However family planning (FP) programs generally do not recognize the role of male attitudes and attributes in fertility-related decision making $[3,4,5,6,7]$. There is a need to explore how power dynamics within relationships affect women's reproductive aspirations and behaviors and how women's contraceptive behaviors are affected by the perceived fertility desires of their male partners. This information can be used by programs to help women control their fertility [9]. Men tend to have the dominant influence in household decision-making, including fertility and family planning, but surveys in Africa suggest that men and women do not necessarily have similar fertility attitudes, perceived roles, and goals $[3,4,8,9]$. Exploration of couple's fertility dynamics is urgently needed for program strategies to reduce unmet need, unintended pregnancies and expand family planning use.

Although current literature on fertility decision making in SSA strongly suggests that men play an important and often dominant role in couples' adoption of contraception $[10,11]$, there is limited empirical data on whether male attitudes are either perceived or true barriers to use of contraception by women. We know little about how women reconcile the desire for children within patriarchal families where they are less empowered to make important fertility and contraceptive decisions for themselves.

Uganda, is a patriarchal society, with one of the highest annual population growth rates in the world ( $3 \%$ per annum), the highest Total Fertility Rate (TFR) in East Africa of 5.4 children per woman, and a modern contraceptive prevalence among married women of $35 \%[12,13]$. The aim of this analysis was to conduct a prospective assessment on couples to understand how the women's perception of their spouse's fertility desires affects her use of female controlled modern contraception. The strength of our couple's analyses is that we were able to assess how accurate a woman's perception of her spouse's fertility desires was, by examining her partner's fertility desires. This study fills an important gap in our understanding of the role of male desires and decision making around fertility decisions and to assess to what extent women's perceptions of their spouse's attitude is a barrier to use of contraception.

\section{Methods}

We used data from an open community-based cohort, the Rakai Community Cohort Study (RCCS) which has been described elsewhere [14,15]. In brief, each RCCS participant receives a unique, life-long identification number used to link data over time. Participants sign a written informed consent for study participation, sample collection and HIV testing. The RCCS survey, includes all consenting residents aged 15-49 years ( $n \sim 12,000$ per survey). Experienced same-sex interviewers, fluent in the local language, have been trained to ensure participant privacy and confidentiality. Participants are administered a

Correspondence to: Tom Lutalo, Rakai Health Sciences Program, Uganda Virus Research Institute, Entebbe, Uganda. Email- tlutalo@rhsp.org

Received: September 17, 2017; Accepted: October 06, 2017; Published: October 09,2017 
structured questionnaire to assess socio-demographic characteristics, sexual risk behaviors, fertility desires and intention, perceptions of spouse's fertility desires, pregnancy history, contraceptive use and health/health care seeking information.

Using two surveys rounds 15 and 16; between July 2011 to May 2013 and June 2013 to January 2015, respectively, we examined participant's fertility desires, perceptions of spouse's fertility desires and women's use of female controlled modern contraception among couples linked retrospectively. These were the only survey rounds when data on fertility perceptions and partner's fertility desires were collected. Partner information was obtained via questions on sexual networks and by linkage information that allows identification of male partners in marital or consensual relationships.

\section{Definitions of variables used}

i) For fertility desires, individuals were asked whether they would like to have a child in the next twelve months.

ii) For fertility perceptions, individuals were asked whether their spouse wanted to have a child in the next twelve months. Responses included Yes, No and Don't Know.

iii) Women reporting current use of oral contraception, injectables, spermicides, Intrauterine Devices (IUD) or implants were considered to be using female controlled modern contraception.

\section{Ethical consideration}

The RCCS and its procedures were approved by the Uganda Virus Research Institute's Science and Ethics Committee (currently the Research Ethics Committee), the Uganda National Council for Science and Technology and Institutional Review Boards (IRB) at Johns Hopkins and Columbia Universities, and Western IRB in the USA. The Makerere University School of Public Health IRB approved this analysis.

\section{Statistical analysis}

For this analysis we excluded couples where the female was pregnant or reported infertility or any member of the couple reported sterilization. We also excluded couples where the female did not have a definite response to the question on spouse's fertility desires (perception of spouse's fertility desire=Don't Know). Polygamous men formed unique couples with each of their female partners.

Chi-square tests were used to assess within-couple differences in fertility desires and whether there were differences between the female's perceptions of their spouse's fertility desires and the reported fertility desires of the male spouse.

We used mediation analysis (or path analysis) for this study. It was hypothesized that women's perception of their spouse's fertility desires might have an indirect effect on their use of modern contraception. The logic behind this is that women's perception of their spouse's fertility desires might indirectly mediate (indirect effect) their own fertility desires (mediator) thus indirectly determining their use/non-use of female controlled modern contraception. The rationale was that some of the effect of the Independent Variable (i.e., female's perceptions of spouse's fertility desires) is transmitted to the Dependent Variable (use of female controlled modern contraception) through the Mediator Variable (Female's fertility desires). The proportion of the effect of the Independent Variable via the Mediator Variable is an estimate of the indirect effect.
The analysis used the program ml_mediation in STATA 13 which can be used for longitudinal multilevel data [16].

The mediation analysis used three equations:

The first equation modeled the Dependent Variable on the Independent Variable (use of female controlled modern contraception on female's perception of spouse's fertility desire);

The second equation modeled the Mediation Variable on the Independent Variable (female's fertility desire on female's perception of spouse's fertility desires);

The third equation modeled the Dependent Variable on the Mediation Variable and the Independent Variable (use of female controlled modern contraception on female's fertility desires and perceptions). This is the model that generated the total direct effect, the total indirect effect and the total effect.

However results can only be used if the models pass the following tests;-

The Independent Variable must be a significant predictor in the first model

The Independent Variable must be a significant predictor of the Mediator Variable in the second model.

The Independent Variable may not be significant (complete mediation) when the Mediator Variable is included in the model which suggests mediation.

In order to achieve statistical robustness and reasonable estimates of the confidence intervals we used the bootstrap method (multiple replications with replacement) using the indirect, direct and total effects from the output

\section{Results}

A total of 2,636 couples were included in the analysis. Most of the participants were aged $25-34$ years $(48.5 \%$ for females and $43.1 \%$ for males), had completed primary education (67\% for females and $68.6 \%$ for males) and resided in rural communities (51\%; Table 1). $43.8 \%$ of women had 1-2 living children while $35.9 \%$ of men had 3-5 living children. The median number of children for moth males and females was 3 . Use of modern contraception by both members of the couple (male condom and/or any other reported modern contraceptive method by the female partner, $\mathrm{F}+\mathrm{M}+$ ) was reported by $37.3 \%$ of the couples while $34.6 \%$ reported nonuse (by both members of the couple, F-M-). There were $16.8 \%$ of the couples where only the men reported use $(\mathrm{F}-\mathrm{M}+)$ and $11.3 \%$ where only the females reported use of contraception $(\mathrm{F}+\mathrm{M}-)$.

\section{Fertility desire within couples}

Concordance in fertility desire was $69.4 \%$, and was higher when both members of the couple did not want a child in the next 12 months $(53.1 \%)$ and lowest when both wanted a child (16.3\%; Table 2). When discordance in fertility desire (30.6\%) was determined by sex, $23.6 \%$ was due to males desiring a child while females did not, and $7 \%$ was due to females desiring a child while males did not desire a child in the next 12 months. Within couples, more women (2023; 76.8\%) than men $(1584 ; 60.1 \%)$ did not want to have a child in the next 12 months $(\mathrm{p}<001)$.

Female's perception of male spouse's fertility desires compared to reported male spouse's fertility desires

In $53.9 \%$ of the couples there was concordance between the female's perception of their male spouse's fertility desires and the reported 
Table 1. Socio Demographic characteristics of individuals forming couples in the analysis at baseline

\begin{tabular}{|c|c|c|c|}
\hline Characteristics & Females & Males & p-value \\
\hline $\mathrm{N}$ & 2636 & 2636 & \\
\hline \multicolumn{4}{|l|}{ Age group } \\
\hline $15-24$ & 28 & 8 & $<0.001$ \\
\hline $25-34$ & 48.5 & 43.1 & \\
\hline $35-44$ & 21.7 & 39.5 & \\
\hline $45+$ & 1.8 & 9.5 & \\
\hline \multicolumn{4}{|l|}{ Education Status } \\
\hline None & 5.5 & 4.5 & 0.211 \\
\hline Some Primary & 67 & 68.6 & \\
\hline Post Primary & 25.6 & 27 & \\
\hline \multicolumn{4}{|l|}{ Residence } \\
\hline Rural & 50.8 & & \\
\hline Peri-Urban & 15.1 & & \\
\hline Fishing Community & 34.1 & & \\
\hline \multicolumn{4}{|l|}{ HIV Status } \\
\hline Negative & 74.9 & 74.9 & 0.093 \\
\hline Positive & 21.4 & 20.3 & \\
\hline UnKnown & 3.7 & 4.9 & \\
\hline \multicolumn{4}{|l|}{$\begin{array}{l}\text { Reported Use } \\
\text { of Modern } \\
\text { Contraception }\end{array}$} \\
\hline Yes & $48.6^{*}$ & 54.1 & $<0.001$ \\
\hline No & 51.4 & 45.9 & \\
\hline \multicolumn{4}{|l|}{$\begin{array}{l}\text { Household Wealth } \\
\text { Index }\end{array}$} \\
\hline Low & 25.2 & & \\
\hline Middle & 23.3 & & \\
\hline High & 51.5 & & \\
\hline \multicolumn{4}{|l|}{$\begin{array}{l}\text { Number of Living } \\
\text { Children }\end{array}$} \\
\hline None & 13.2 & 3.1 & $<0.001$ \\
\hline $01-\mathrm{Feb}$ & 43.8 & 26.7 & \\
\hline 03-May & 30.3 & 35.9 & \\
\hline $6+$ & 12.7 & 34.3 & \\
\hline
\end{tabular}

*includes reported use of male condoms

Table 2. Within couple differentials in fertility desires**

\begin{tabular}{|c|c|c|c|c|}
\hline \multirow{3}{*}{$\begin{array}{c}\text { Male Desires a } \\
\text { child in the next } 12 \\
\text { Months }\end{array}$} & \multicolumn{3}{|c|}{$\begin{array}{c}\text { Female Desires a child in the next } 12 \\
\text { months }\end{array}$} & \multirow{3}{*}{ Total } \\
\hline & Yes & \multirow[t]{2}{*}{ No } & \multirow[t]{2}{*}{$(\%)$} & \\
\hline & & & & \\
\hline Yes & $429(16.3)$ & 623 & $(23.6)$ & 1052 \\
\hline No & $184(7.0)$ & 1400 & $(53.1)$ & 1584 \\
\hline Total & 613 & & & 2636 \\
\hline
\end{tabular}

$* * \mathrm{p}<0.001$

fertility desires of the male spouse; in $29.9 \%$ the male desired a child and the female correctly perceived this preference, and in $24 \%$ the male did not desire a child and the female correctly perceived it (Table 3 ). However, in $28.9 \%$ of couples females thought the man desired a child while the male did not desire a child while in $7.1 \%$ of couples, females thought the man did not desire a child while the male did desire a child in next 12 months.

\section{Mediation analysis results}

All the mediator analysis assumptions were met. The first model showed that the female's perception of their spouse's fertility desire is a significant predictor of their modern female controlled contraceptive use $(\mathrm{p}<0.001$; Table 4$)$.
The second model showed that the female's perception of their spouse's fertility desire was a significant predictor of the female's fertility desires ( $<<0.001$; Table 5$)$ and in the third model, the female's fertility desire was a significant predictor of female controlled modern contraceptive use $(\mathrm{p}<0.001$; Table 6).

The indirect, direct and total effect of the mediating variable (fertility desires) generated using the bootstrap method is shown in Table 7 . The indirect effect was significant $(11 \%, \mathrm{p}<0.001)$; indicating that female's perception of their spouse's fertility desires is significantly mediated through the woman's own fertility desires and this relationship, though indirect, effects the use of female controlled modern contraception.

\section{Discussion}

Our study found that women's perception of their partners fertility desires has a significant impact on their use of modern contraception. However a good proportion of the women (29\%) perceived their partners desired a child in the next 12 months but the men reported no desire for a child. The majority of couples had similar fertility desires with most not wanting to have a child in the next 12 months, but more women than men did not want to have a child in the next 12 months.

This necessitates a need to promote increased participation of both members of a couple in order to promote agreement and concordance regarding use of contraception. Spousal communication, once promoted would help perceptions and actual desires within a couple in this setting. Research has demonstrated a positive relationship between spousal communication and contraceptive use in African settings [5].

A study in Ethiopia observed that the promotion of male involvement in FP would influence the policy environment to be more conducive to promoting couple based programs [2]. Involvement of both members of a couple gives them the ability to choose the number and spacing patterns of their children through utilization of FP.

It has also been shown that improving utilization of FP services in developing countries could significantly reduce infant mortality and maternal deaths [17]. Therefore programs that could help merge perceptions and actual desires within couples in this setting would benefit National Population Plans.

Understanding the influences of fertility and contraceptive use in settings with high levels of fertility and unmet need are important in order for reproductive health interventions and services to be more effective.

Our study found that female fertility desires were indirectly influenced by their perceptions of the male spouse's fertility desires which affected their use of modern contraception. We also found that $58.8 \%$ of women had a perception that their spouses desired a child in the next 12 months, and this perception had a significant indirect effect on their use of female controlled modern contraception, with their fertility desires acting as the mediating factor.

This suggests that the promotion of couple family planning counseling could improve fertility discussions in this patriarchal Ugandan society. If households are targeted by family planning programs to promote contraceptive use and reduce fertility, the policy could hinge upon the promotion of couple discussions. For programs that promote FP at community centers there is a need to strongly encourage men to escort their female spouses to promote couple informed decisions. 
Table 3. Female's Perception of male spouse's fertility desires compared to actual desires of the male partner

\begin{tabular}{|c|c|c|c|c|c|}
\hline \multirow[t]{2}{*}{$\begin{array}{l}\text { Female's perception of their spouse's } \\
\text { fertility desires }\end{array}$} & \multicolumn{3}{|c|}{$\begin{array}{l}\text { Male partner's reported fertility desires in } \\
\text { the next } 12 \text { months }\end{array}$} & & \multirow[t]{2}{*}{ Total } \\
\hline & Yes $\quad(\%)^{*}$ & No & $(\%)$ & & \\
\hline Male partner desires a child & $(29.9)$ & & & $762 \quad(28.9)$ & 1550 \\
\hline \multirow[t]{3}{*}{ Male partner does not desire a child } & & & & $(24.1)$ & 822 \\
\hline & $(7.1)$ & & & & \\
\hline & $(2.9)$ & & & $188 \quad(7.1)$ & 264 \\
\hline \multicolumn{6}{|l|}{ Don't Know } \\
\hline Total & 1052 & & & 1584 & 2636 \\
\hline
\end{tabular}

*cell proportions

Table 4. Modeling modern contraceptive use on female's perception of their partner's fertility desires

\begin{tabular}{|c|c|c|c|c|}
\hline Female's use of modern contraception & Coef. & Std Err. & z & P5\% Conf. Interval \\
\hline Perception of partner's fertility desires & 0.113 & 0.0195 & 5.79 & 0 \\
\hline Constant & 0.382 & 0.0122 & 31.44 & $0.075-0.151$ \\
\hline
\end{tabular}

Table 5. Modeling female's short term fertility desires on female's perception of their partner's fertility desires

\begin{tabular}{|c|c|c|c|c|}
\hline Female's use of modern contraception & Coef. & Std Err. & $\mathbf{z}$ & P> $>|\mathbf{z}|$ \\
\hline Perception of partner's fertility desires & 0.113 & 0.0195 & 5.79 & 0 \\
\hline Constant & 0.382 & 0.0122 & 31.44 & $0.075-0.151$ \\
\hline
\end{tabular}

Table 6. Modeling female's short term fertility desires on female's perception of their partner's fertility desires

\begin{tabular}{|c|c|c|c|c|}
\hline Female's use of modern contraception & Coef. & Std Err. & Z & 95\% Conf. Interval \\
\hline Female's short term fertility desires & 0.324 & 0.232 & 13.94 & 0 \\
\hline Perception of partner's fertility desires & 0.003 & 0.02 & 0.16 & 0.872 \\
\hline Constant & -0.144 & 0.04 & -3.65 & 0.369 \\
\hline
\end{tabular}

Table 7. The significance of the indirect, direct and total effect of female's perception of partner's fertility desire on their use of modern contraception

\begin{tabular}{|c|c|c|c|c|c|}
\hline & Observed & \multirow{2}{*}{$\begin{array}{c}\text { Bootstrap } \\
\text { Std Err. }\end{array}$} & \multirow{2}{*}{$\mathbf{z}$} & \multirow{2}{*}{$\mathbf{P}>|\mathbf{z}|$} & \multirow{2}{*}{$\begin{array}{c}\mathbf{9 5 \%} \text { Conf. } \\
\text { Interval }\end{array}$} \\
\hline & Coef. & & & & \\
\hline Indirect effect & 0.113 & 0.009 & 12.33 & 0 & $0.095-0.131$ \\
\hline Direct effect & 0.003 & 0.019 & 0.18 & 0.86 & $-0.033-0.040$ \\
\hline Total effect & 0.116 & 0.017 & 6.72 & 0 & $0.082-0.150$ \\
\hline
\end{tabular}

The study observed that males have higher fertility desires compared to women within a couple. This is similar to another study which observed higher fertility desires among men (70\%) compared to women (57\%) in a similar setting [18]. When discordance in fertility desire was observed, more men compared to women had a desire for a (another) child. Programs should endeavor to promote consensus in order to harmonize fertility behavior in this setting. Consensus can be promoted once programs move away from the perception that reproductive health was a woman's domain due to gender norms and traditional pronatalist beliefs and tendencies as has been observed in some studies [19].

\section{Study limitations}

Limitations of this study include information bias where respondents give inaccurate information or information that is socially desirable. This was minimized by thoroughly explaining to the participants at the time of consent the need for accurate information and by the use of well trained and experienced interviewers.

Another limitation might be recall bias which was minimized by the flow of the questions to help respondents focus and remember answers to prior questions. Findings may not be generalizable to the general Ugandan population.

\section{References}

1. Dodoo NAF (1998) Men matter: Additive and interactive gendered preferences and reproductive behavior in Kenya. Demography, 35: 229-242. [Crossref]
2. Walle Y, Alamrew Z (2014) The Current States of Male Involvement on Family Planning and Factors Correlated with among Male Factory Workers in Bahir Dar City. Am J Public Health Res, 2: 188-197.

3. Mbizvo MT, Adamchak DJ (1991) Family planning knowledge, attitudes, and practices of men in Zimbabwe. Stud Fam Plann 22: 31-38. [Crossref]

4. Ezeh A (1993) The influence of spouses over each other's contraceptive attitudes in Ghana. Stud Fam Plann, 24: 163-174.[Crossref]

5. Bawah AA (2002) Spousal Communication and Family Planning Behavior in Navrongo: A Longitudinal Assessment. Stud Fam Plann, 33: 185-194. [Crossref]

6. Aransiola JO, Akinyemi AI, Fatusi AO (2014) Women's perceptions and reflections of male partners and couple dynamics in family planning adoption in selected urban slums in Nigeria: a qualitative exploration. BMC Public Health, 14: 869. [Crossref]

7. Muanda M, Gahungu Ndongo P, Taub LD, Bertrand JT (2016) Barriers to Modern Contraceptive Use in Kinshasa, DRC. PLoS One 11: e0167560. [Crossref]

8. Mosha I, Ruben R, Kakoko D (2013) Family planning decisions, perceptions and gender dynamics among couples in Mwanza, Tanzania: a qualitative study. BMC Public Health, 13: 523. [Crossref]

9. Bankole A (1995) Desired Fertility and Fertility Behaviour amnong the Yoruba of Nigeria: A study of Couple Preferences and Subsequent Fertility. Population Studies, 49: 317-328.

10. Speizer IS, Whittle L, Carter M (2005) Gender relations and reproductive decision making in Honduras. Int Fam Plan Perspect 31: 131-139. [Crossref]

11. Vouking MZ, Evina CD, Tadenfok CN (2014) Male involvement in family planning decision making in sub-Saharan Africa- what the evidence suggests. Pan Afr Med J., 19: 349. [Crossref]

12. Akullq E (2012) The role of education and social entrepreneurship in advancing gender equality. United Nations Commission on the Status of Women. Retrieved from www. un.org/womenwatch/daw/.../panel-5-emerging-theme-Akullq.pdf

13. Uganda Bureau of Statistics (UBOS) and ICF. (2017). Uganda Demographic and Health Survey 2016: Key Indicators Report.

14. Wawer MJ1, Gray RH, Sewankambo NK, Serwadda D, Paxton L, et al. (1998) A randomized, community trial of intensive sexually transmitted disease control for AIDS prevention, Rakai, Uganda. AIDS, 12: 1211-1225. [Crossref] 
15. Wawer, M. J., Sewankambo, N. K., Serwadda, D., Quinn, T. C., Paxton, L. A., Kiwanuka, N., . . . Gray, R. H. (1999). Control of sexually transmitted diseases for AIDS prevention in Uganda: a randomised community trial. Rakai Project Study Group. Lancet, 353: 525-535. [Crossref]

16. Krull JL, MacKinnon DP (1999). Multilevel mediation modeling in group based intervention studies. Eval Rev 23: 418-444. [Crossref]

17. Chola L, McGee S, Tugendhaft A, Buchmann E, Hofman K (2015). Scaling Up Family Planning to Reduce Maternal and Child Mortality: The Potential Costs and Benefits of Modern Contraceptive Use in South Africa. PLoS One, 10: e0130077. [Crossref]
18. Matovu JK, Makumbi F, Wanyenze RK, Serwadda D (2017). Determinants of fertility desire among married or cohabiting individuals in Rakai, Uganda: a cross-sectional study. Reprod Health, 14: 2. [Crossref]

19. Kabagenyi A, Jennings L, Reid A, Nalwadda G, Ntozi J, et al. (2014). Barriers to male involvement in contraceptive uptake and reproductive health services: a qualitative study of men and women's perceptions in two rural districts in Uganda. Reprod Health, 11, 21-21. [Crossref]

Copyright: (C2017 Lutalo T. This is an open-access article distributed under the terms of the Creative Commons Attribution License, which permits unrestricted use, distribution, and reproduction in any medium, provided the original author and source are credited. 